\title{
Evidence-Based Assessment of Child Obsessive Compulsive Disorder: Recommendations for Clinical Practice and Treatment Research
}

\author{
Adam B. Lewin · John Piacentini
}

Published online: 8 January 2010

(C) The Author(s) 2010. This article is published with open access at Springerlink.com

\begin{abstract}
Obsessive-compulsive disorder (OCD) presents heterogeneously and can be difficult to assess in youth. This review focuses on research-supported assessment approaches for OCD in childhood. Content areas include pre-visit screening, diagnostic establishment, differential diagnosis, assessment of comorbid psychiatric conditions, tracking symptom severity, determining psychosocial functioning, and evaluating clinical improvement. Throughout this review, similarities and differences between assessment approaches geared towards clinical and research settings are discussed.
\end{abstract}

Keywords OCD $\cdot$ Obsessive-compulsive-disorder $\cdot$ Assessment $\cdot$ Child

Conventionally, assessment of childhood obsessive compulsive disorder (OCD) in research settings has focused on systematic categorization of diagnosis and symptoms using a barrage of interviews and questionnaires whereas community-based evaluations have been generally based on of unstructured clinical interviews. Nevertheless, there is an increasing movement towards evidence-based assessment in child psychiatry, and assessment techniques from clinical research are becoming more commonplace in practice settings. This article summarizes critical content areas (e.g., pre-visit screening, establishment of the diagnosis, differential diagnosis, identifying comorbidity, tracking symptom severity, determining psychosocial functioning, and evaluating outcome/clinical improvement) for any assessment of childhood OCD. Throughout this review, similarities and differences between assessment approaches geared towards clinical and research settings are discussed. The aim of this article is to provide an overview of research-supported approaches for the assessment of youth with OCD relevant to both research and clinical applications.

\footnotetext{
A. B. Lewin $(\bowtie)$

Department of Pediatrics, Rothman Center for Neuropsychiatry, University of South Florida College of Medicine, 800 Sixth Street South, Fourth Floor North, Box 7523, Saint Petersburg, FL 33701, USA e-mail: alewin@health.usf.edu
}

A. B. Lewin · J. Piacentini

Department of Psychiatry \& Biobehavioral Sciences, University of California Los Angeles Semel Institute for Neuroscience and Human Behavior, Los Angeles, CA, USA 


\section{Pre-Visit Screening}

Prescreening prior, to a comprehensive assessment or intake, can be an important tool in both clinical and research settings. Childhood OCD treatment and research is often conducted in specialty treatment programs. Consequently, pre-office visit screenings are commonplace to maximize effective use of examiner's and patient's time. In many settings, the screening is the first assessment component. The purpose of the initial screening in research settings is to efficiently determine potential eligibility of the child for a given research project and is generally limited to a review of the inclusion (and exclusion) criteria for the study (for example, obtaining symptom report from a parent that suggests the presence of OCD in his/her child). Screenings may be conducted in-person or via telephone and can be provider or subject initiated. Although screening interviews or questionnaires may be structured, open-ended, or a combination of both approaches, they are not considered substitutes for more thorough diagnostic workups. Although screening typically occurs prior to IRB consent, procedures are often overseen by an institution's Human Subjects Research Board.

Similarly, in clinical settings, clinicians often attempt to identify presenting problems of new patients (to ensure overlap with their practice's focus or personal expertise) prior to the initial visit. Similar to a visit to a medical specialist, this information may be collected via an intake questionnaire/checklist mailed to the family (which obtains background information that may be useful in structuring the intake and/or determining whether outpatient CBT for OCD is the appropriate intervention).

\section{Establishing the Diagnosis of OCD}

Regardless of whether the assessment occurs in a research or clinical setting, establishing the OCD diagnosis is the key component of an initial assessment. Accurate diagnosis is the foundation for clinical documentation, communication with other healthcare practitioners, and serves as a basis for initiating evidence-based mental health treatment.

Diagnostic Interviews: Structured diagnostic interviews, specifically based upon the criteria outlined in the Diagnostic and Statistical Manual of Mental Disorders, 4th Edition, Text Revision (DSM-IV-TR; American Psychiatric Association 2000) are commonly employed in research assessments of childhood OCD. Diagnostic interviews allow for a systematic review of current and past symptoms of OCD and potential co-occurring psychopathology in order to facilitate differential diagnosis. Aside from comprehensiveness, advantages of diagnostic interviews include (a) demonstrated reliability and validity (Kaufman et al. 1997; Silverman et al. 2001; Wood et al. 2002) (b) allow for relatively consistent administrations across youth, and (c) facilitate systematic gathering of parent, child and/or combined reports of symptoms. However, the comprehensiveness of the structured interview is not without cost. Most structured diagnostic interviews require extensive training, are time intensive (in youth with OCD, usually in excess of 60-90 min), necessitate the purchase of materials and manuals, and are not treatment-focused (i.e., information from diagnostic interviews does not typically influence treatment decisions other than by highlighting comorbidities or providing ordinal estimates of symptom severity).

The most commonly used clinician-administered diagnostic interviews among youth with OCD are the Anxiety Disorders Interview Schedule for DSM-IV: Child and Parent Version (ADIS-C/P; Silverman and Albano 1996), the Schedule for Affective Disorders and Schizophrenia for School-Age Children-Present \& Lifetime version (K-SADS-PL; 
Kaufman et al. 1997), and the National Institute of Mental Health Diagnostic Interview Schedule for Children (NIMH-DISC or DISC; Shaffer et al. 2000). Children and parents are typically interviewed separately and the clinician combines information obtained from both informants, using clinical judgment, to assign diagnoses and corresponding scores of diagnostic severity. The majority of questions in the ADIS-C/P focus on anxiety disorders whereas the DISC and K-SADS-PL covers a broader range of psychiatric syndromes (especially non-anxiety and non-internalizing conditions). The ADIS is generally considered the strongest measure for clinical assessment and treatment-outcome research among youth with OCD; the current version (Silverman and Albano 1996) contains sections assessing broader ranges of non-anxiety comorbidity (including Tourette's and other tic disorders). Detailed reviews of these and other diagnostic measures are available (e.g., Grabill et al. 2008; King and Scahill 1999; Langley et al. 2002; Lewin et al. 2005; Merlo et al. 2005).

There are several reasons that systematic diagnostic procedures are important in OCD research. First, they allow for confirmation of the OCD diagnosis. Second, given the widerange of other symptoms assessed, the presence of additional diagnoses can be classified (and exclusionary cases can be identified). Third, in cases of multiple concurrent diagnoses, structured interviews, most notably the ADIS, allow for a relatively consistent method for assessing which condition is most severe.

Clinical Intakes: Establishing an OCD diagnosis is also important in clinical assessments, albeit for potentially different reasons. Unlike research assessments, which are typically geared to classify and quantify, clinical assessments aim to conceptualize the case and tailor the treatment around the patient's history, symptoms, and other individual/family characteristics. Consequently, the treatment intake is conducted, ideally, by the treating clinician (as opposed to the research setting wherein the diagnostic procedure may be implemented by a research assistant or independent evaluator, under the supervision of a licensed clinician). Outside of academic centers, clinical interviews are usually the modus operandi. Although measures such as the ADIS-C/P are increasingly employed in clinical settings, unstructured interviews are more commonly utilized. This may be due to clinician preference, expense/ training associated with the structured materials, or difficulty in obtaining insurance reimbursement for measures that exceed a more conventional 60-min diagnostic interview.

In the absence of a formal diagnostic measure, the use of a DSM-based checklist covering all of the criteria for OCD is recommended. This information can be useful in organizing the clinical picture as well as for documenting accurate diagnostic-based information in the patient's chart.

Informant Bias. In childhood, the diagnostic process can be particularly complex given that a child's report and interpretation of his/her symptoms may be of insufficient detail or descriptiveness to accurately and reliably characterize a disorder. Similarly, limited insight (Lewin et al. in press-a) or embarrassment (Jenike 1989) may lead to minimization of symptoms. Consequently, inclusion of parent report (and/or other adult corroboration) is typically necessary. While structured interviews can be helpful in improving the reliability of a diagnosis, accuracy is not guaranteed. For example, the parent of a child with pervasive developmental disorder may describe her son's "obsessions" with fire extinguishers and sprinklers and his "compulsion" to spin and twirl in their presence.

\section{Differential Diagnosis}

As in adults, childhood OCD is characterized by (1) the presence of recurrent, persistent and intrusive thoughts (obsessions) and/or repetitive ritualistic behaviors or mental acts 
(compulsions) and (2) the presence of the obsession/compulsions causes marked distress, is time consuming, or interferes with normal functioning (APA 2000). Nevertheless, there are a number of behavioral topographies associated with non-OCD psychiatric syndromes that may present similarly to OCD (Lewin and Piacentini 2009). For example, a hallmark of tic disorders is the presence of repetitive movements; youth with autism often engage in elaborate rituals; a patient with anorexia nervosa may obsess about eating-related behaviors; trichotillomania can be characterized as compulsive hair-pulling. To further complicate matters, these syndromes may co-occur with OCD, complicating the differential and obfuscating characterization of a patient's specific symptoms to the respective disorder.

In summary, many differentials are not clear-cut. Until neurobiological research contributes reliable biomarkers for specific illnesses, clinicians must infer (as best they can from history, presenting symptoms, and observation) the nature of the psychopathologynot only for the purposes of classification per se, but to guide intervention (treatment for OCD and schizophrenia or autism vary considerably). Thus, the purpose of the discussion below is to alert the reader to overlapping symptoms and to offer initial directions for distinguishing between syndromes.

Tic Disorders. Determining the presence or absence of a tic disorder among youth with OCD is often relatively straight forward. However, differentiating tics from compulsions, among comorbid youth, can be challenging. Simple phonic or motor tics (e.g., sniffing, eye blinks, and throat clearing) can usually be differentiated from compulsions by virtue of their brevity, simplicity, lack-of-purpose, and often involuntary nature (Mansueto and Keuler 2005). However, complex motor tics (e.g., repeating a particular action until it feels right) can be more difficult to distinguish from compulsions (Castellanos 1998; Mansueto and Keuler 2005). The relevance of the distinction is magnified by the high, bidirectional association between OCD and tic disorders (including Tourette's Disorder [TD]). Twenty to sixty percent of TD patients meet criteria for OCD, and 20-38\% of children with OCD report comorbid tics (Goodman et al. 2006; Pauls et al. 1995; Swedo et al. 1989).

Symptom topography alone is often insufficient for determining whether a behavior is a tic or compulsion. In fact, many tic-like behaviors present as compulsions among adults with co-occurring OCD and tic disorders. Among adult patients with OCD and tic disorders, repetitive counting, ordering and arranging, symmetry/evening-things-up, blinking/ staring rituals, and touching-tapping-and-rubbing were the most common compulsions (Holzer et al. 1994). Contamination obsessions, washing/cleaning rituals, and checking compulsions were less common in individuals with comorbid tic disorders (George et al. 1993; Holzer et al. 1994; Leckman et al. 1994). Similar patterns have been demonstrated in youth (Hanna et al. 2002; Lewin et al. in press-b; Storch et al. 2007).

The following heuristics may aid in differentiating tics from compulsions. To determine whether a symptom is a tic or compulsion, one should consider the symptom's precursor triggers and reactions to withholding the symptom in the context of the behavioral history. First, try to determine whether the function of the symptom is distress-reduction or urgerelief. Ask if the child reports engaging in the symptom to (a) alleviate anxiety or distress (even if the stressor is vague or indeterminate) or (b) reduce an urge or sensation (localized or generalized). Second, determine whether restraint of the symptom tends to result in anxiety vs. physical/sensory discomfort. Ask the child, "What happens/how do you feel" if they refrain from engaging in the symptom (or ask "what do you think would happen/how would you feel," if they report never refraining). Evaluate for responses resembling (a) "something bad might happen," "I'd feel stressed," or "I could never do that," versus (b) "I can't hold it in/it's too hard to control," "the urge would just get stronger," or 
"probably nothing." Finally, consider the symptom in context. For example, is the child's history (a) remarkable for anxiety, clear-cut obsessions/compulsions or (b) is the history relatively lacking in anxiety but noteworthy for simple phonic and motor tics. Although compulsive behaviors can occur in the absence of obsessions, Foa et al. (1995) found only $1.7 \%$ of 411 adult patients with OCD to present in this fashion (Foa et al. 1995).

Differentiating between OCD and tic disorders has significant treatment implications given differing pharmacological interventions for the two disorder (Goodman et al. 2006). However, behavioral interventions for tics and compulsions draw upon the same basic techniques (e.g., extinction, reduction of reinforcement for problematic behavior; Piacentini and Chang 2006) such that some experts suggest that distinguishing between tics and compulsions is not always necessary (Mansueto and Keuler 2005).

Generalized Anxiety Disorder. Obsessive Compulsive Disorder and Generalized Anxiety Disorder (GAD) are highly comorbid. Obsessional doubts and ruminations may closely resemble GAD - both are usually experienced as excessive and uncontrollable (Taylor et al. 2002). Further adding to the obfuscation is that individuals with GAD may engage in subclinical rituals (e.g., checking or reassurance seeking; Brown et al. 1993; Taylor et al. 2002; Turner et al. 1992). Turner et al. (1992) and Taylor et al. (2002) discussed the criteria that can assist in distinguishing obsessions from GAD-worry. First, the content of GAD-worry is typically related to normal, everyday experiences (e.g., family, peers, health, school) whereas obsessions are more likely to contain unusual content (e.g., contamination, sexual, religious, and aggressive themes). Second, obsessions are usually described as more intrusive than GAD-worries and individuals often make greater efforts to resist OCD-based obsessions. Third, worries are typically described to occur as thoughts; obsessions may be experienced as thoughts, impulses or images. Finally, the content of obsessions is more likely to be regarded as socially or personally unacceptable (or egodystonic). Fortunately for patients who are stricken by both syndromes, many CBT approaches for OCD and GAD overlap.

Autism Spectrum Disorders. As discussed above, it is not uncommon for stereotyped behaviors and fixated interests associated with autism-spectrum disorders (including Pervasive Developmental Delay Not Otherwise Specified [PDD NOS] and Asperger's Syndrome) to be labeled as obsessions and compulsions. Developmental history is a critical factor in distinguishing between OCD and autism spectrum disorders. For example, clinicians should screen for early history of language delays (not required for all autism spectrum disorders) or stereotyped/idiosyncratic language use, difficulties establishing/ maintaining social interactions, problems reading social cues/non-verbal behavior, stereotyped movements, fixated interests or atypical preoccupations (e.g., parts of a washing machine). Although youth with OCD may not universally consider their symptoms to be egodystonic, youth with autism spectrum disorders often consider their behaviors to be egosyntonic-fixating on subjects of considerable interest (even if excessive or odd; e.g., memorizing all the fire hydrants in their neighborhood, knowing the complete subway schedule for a metropolitan area never having visited, preoccupation with lawn sprinklers). Although symptoms may cause impairment (e.g., difficult to engage them in necessary activities such as school, chores; tantrums may result from disruption of routine), associated distress typically results from being prevented from engaging in a given behavior due to its rewarding nature rather than anticipation of feared consequences.

Anorexia Nervosa. Although obsessions and rituals are central features of anorexia nervosa, these thoughts and behaviors are limited to food and dietary behaviors (e.g., rigidity about eating, inflexibility about dietary and exercise behaviors, obsession with weight and appearance). In a comparative study, Bastiani et al. (1996) found that OCD patients endorsed a wide variety of obsessions and compulsions, whereas patients with 
anorexia tended to endorse ritualistic symptoms that were more specifically related to symmetry and order, despite similar CY-BOCS scores. While OCD commonly occurs among adolescents with anorexia nervosa (Godart et al. 2002; Strober et al. 2007), OCDrelated fears and behaviors can generally be distinguished from anorexia-specific worries and rituals (Jimenez-Murcia et al. 1997). Although severe weight loss can result from contamination-focused OCD (e.g., worries that food is dirty or somehow contaminated), these patients do not endorse the fear of weight gain or altered perception of personal appearance that is are features of anorexia.

Schizophrenia spectrum disorders. There is considerable overlap in observable behaviors among patients with OCD and psychotic disorders (Rodowski et al. 2008). For example, a child with OCD may refuse to eat at a restaurant due to worries that the food is contaminated whereas a child with psychosis may believe that people are trying to poison the food. The persistence of immature magical thinking is also common among both syndromes (Rodowski et al. 2008) and it is often difficult to determine whether this type of thinking serves to modulate anxiety or if it is a product of a psychotic thought processes. Rodowski et al. (2008) caution that bizarre behaviors and atypical or disorganized thoughts should not lead the clinician to presume a schizophrenia spectrum diagnosis-severe OCD in childhood can have a highly heterogeneous presentation and can mimic symptoms of schizophrenia spectrum disorders. Although symptoms of OCD are usually egodystonic, this is not always the case, especially in younger children.

Rodowski et al. (2008) proposed examination of prevalence, insight, course, and treatment response to facilitate distinction between schizophrenia spectrum disorders and OCD. First, base-rates of OCD are considerably higher (as high as 4\% in childhood; Zohar 1999) whereas childhood schizophrenia is extremely rare (Boeing et al. 2007). Prepubertal onset of OCD is not uncommon whereas the onset of schizophrenia prior to adolescents is markedly atypical. Second, the ability to recognize that symptoms are a product of one's own mind can be helpful in differentiating between delusions and obsession. In adults, diagnostic criteria for OCD stipulate that the person recognizes the senselessness or excessiveness of his or her thoughts or behaviors. Thus, the presence of insight may help distinguish obsessive-compulsive disorder from a psychotic process (Goodman et al. 2006). However, even in adults, the degree of insight varies; limited insight is not uncommon in pediatric OCD (Lewin et al. in press-a). Notably, the DSM-IV specifies that children are not required to possess good insight, further complicating the differential. Even if children deny "thought insertion," it is not uncommon for younger individuals to fail to claim obsessive thoughts as products of their own mind. Thus, the developmental trajectory and variable emergence of insight can limit the ability to use the lack of insight as evidence for the presence of psychotic processes (Rodowski et al. 2008).

More global patterns of paranoia, longstanding histories of failing to trust others (even family members), and other signs of disorganized thinking/formal thought disorder can be suggestive of delusional thought content. Finally, it is not uncommon for course and treatment outcomes to aid with differential diagnosis. For example, Rodowski et al. (2008) describe a case in which as a child aged, she was able to express emerging insight that her obsessive symptoms were products of her own mind. Conversely, a patient with a history of unusually thinking and bizarre behavior may experience a shift from obsessional thoughts to delusional guilt and/or paranoid persecution (Insel and Akiskal 1986). Treatment response, in combination with other evidence (e.g., symptom profile and history) can help distinguish between OCD and psychosis in some cases, e.g., response to a SSRI after failing multiple treatments of antipsychotics (Rodowski et al. 2008). 
Other Differential Considerations (see DSM-IV-TR). Trichotillomania should be considered in cases of repetitive hair-pulling, especially in the absence of other stereotyped behaviors or obsessions. Preoccupations focused solely on physical appearance (exaggerations of imaginal/minor defect of a specific part of the body) may indicate a diagnosis of Body Dysmorphic Disorder. Recurrent and exaggerated fears of contracting a disease based on misinterpretation of bodily symptoms may suggest the appropriateness of a Hypochondriasis diagnosis.

In summary, a number or neuropsychiatric conditions mimic the presentation of OCD in youth and consequently parents, or practitioners less-familiar with OCD in childhood, may mistake non-OCD symptoms (such as tics or stereotyped behavior) for compulsions. While standardized questionnaires and structured interviews can provide relative information about the preponderance of clinical symptoms, they alone do not protect against all errors (for example, rating tic symptoms on a scale assessing OCD-compulsions). Consequently, unstructured clinical interviews, observation, and more in-depth clinician-patient interactions may be necessary for accurate differential diagnosis.

\section{Assessment of Comorbidity}

Comorbidity may complicate the presentation of OCD and has been shown to impact OCD severity, impairment, adaptive functioning and treatment response (Huppert et al. 2009; March et al. 2007; Storch et al. 2008). For example, the presence of oppositional behavior may require contingency management strategies and/or augmented parent-training to enhance on-task behavior (Lewin in press); severe depression may necessitate prerequisite therapy and/or psychopharmacology (e.g., to bolster energy, motivation and reduce irritability); comorbid PDD NOS symptoms might suggest a reduction of cognitive and abstract therapeutic components, instead emphasizing concrete, behavioral strategies. Additionally, in the research setting, identification of comorbidity may be required for numerous reasons, including determination for study eligibility, group classification, or for monitoring clinical correlates.

The instruments and techniques discussed below are commonly utilized in both clinical and research settings. While diagnostic interviews (e.g., the ADIS, K-SADS or DISC) can be used to evaluate the presence or absence of sufficient criteria for a DSM-IV-TR disorder, a variety of self-report measures can provide dimensional information on commonly occurring clinical correlates (e.g., depressive and anxious symptoms, tics, and Attention Deficit Hyperactivity Disorder [ADHD] symptoms). Ideally, reports from multiple respondents are obtained (e.g., child, one or both parents, and teachers). For example, the Child Behavior Checklist (Achenbach 1994) is an extensively-used parent-report of child behavioral and emotional problems with well-documented psychometric properties. The CBCL yields age and gender normalized, broad-based scores for internalizing symptoms (e.g., mood, anxiety), externalizing behaviors (for example, oppositional, inattentive), and adaptive functioning. A number of subscale scores are also generated, e.g., withdrawn behavior, somatic complaints, anxious/depressed, social problems, thought problems, attention problems, delinquent behavior, aggressive behavior, school performance, and social functioning. Child and teacher report formats are also available. The Behavior Assessment System for Children (BASC; Reynolds and Kamphaus 2002) is a comparable, broad-based screener of child symptoms and has parent, teacher and youth report versions.

The Children's Depressive Inventory (CDI, Kovacs 1992) and the Multidimensional Anxiety Scale for Children (MASC; March et al. 1997) are self-report measures commonly 
used in pediatric OCD clinical and research applications. Both are extensively-validated measures of depressive and anxious symptoms (respectively) and yield age and gender corrected T-Scores. The Connors Parent/Teacher Rating Scales (e.g., Conners et al. 1998) and the SNAP/SWAN (e.g., Swanson 1992) are teacher/parent rated measures of symptoms associated with ADHD. The Yale Global Tic Severity Scale (YGTSS; Leckman et al. 1989) is a clinician-rated semi-structured inventory (usually used in research) to assess multiple severity dimensions of motor and vocal tics (frequency, intensity, complexity, strength, and interference) as well as tic-related impairment. Additional broad-based or symptom specific measures may also be required dependent on the nature of the research protocol.

\section{Assessment of OCD Severity}

The identification and rating of OCD symptoms is important component of evidence-based assessment. For example, evaluating and monitoring clinical symptoms can aid the clinician to track particularly troublesome symptoms that may be less responsive to treatment efforts. The Children's Yale-Brown Obsessive Compulsive Scale (CY-BOCS; Scahill et al. 1997), a clinician-rated, semi-structured inventory of pediatric OCD symptoms and severity over the previous week, is considered the gold-standard instrument commonly employed in clinical and research applications. The first section of the CY-BOCS assesses current and life-long presence of common obsessive and compulsive symptoms (e.g., religious obsessions, contamination worries, checking, counting, and cleaning). Subsequently, obsessions and compulsions are rated in terms of their frequency, interference, distress, ability to which they can be resisted, and perceived control over symptoms. A number of child and parent report measures can supplement the CY-BOCS (see Grabill et al. 2008 and Merlo et al. 2005 for reviews). Data from both sections of the CY-BOCS can be helpful in tracking treatment outcome given that not all OCD symptoms for a given child respond equally well to treatment. Additional CY-BOCS items assess dimensions such as a child's lack-of-insight—a factor linked to poor outcome (Storch et al. 2007a, b, c). There is support for the use of self- and parent- report versions of the CY-BOCS for certain applications (Gallant et al. 2008; Storch et al. 2006) although research demonstrates superiority of clinician-administered CY-BOCS to self-report assessment of OCD severity (Storch et al. 2006).

\section{Assessing Psychosocial \& Adaptive Functioning}

Assessments of youth with OCD should include an examination of the child's overall psychosocial functioning. Specifically, impairment in family social and academic domains is commonplace among youth with OCD (Ivarsson et al. 2008; Piacentini et al. 2003, 2007). Increasingly, psychosocial impairment is being tracked as an outcome marker (or clinical correlate) in studies of pediatric OCD (Barrett et al. 2008). Consquently, instruments to assess impairment are commonly used in researching childhood OCD (although they can also be helpful in clinical settings; see below). The Global Axis of Functioning (GAF; American Psychiatric Association 2000) is a single, numeric scale (ranging from 1 [lowest] through 100 [superior]) used by mental health professionals to rate overall social, occupational, and psychological functioning. Similarly, the Global Assessment Scale for Children (CGAS; Shaffer et al. 1983) is a single-item measure of global impairment and 
functioning over the previous month. The scale ranges from 1 (lowest) to 100 (highest) functioning. Alternatively, the Child Obsessive Compulsive Impact Scale-Revised, Parent and Child Reports (COIS-RP, COIS-RC; Piacentini et al. 2007) are parallel parent and youth report questionnaires designed to assess the OCD-specific academic, social, and home/family impairment among youth with OCD.

Family functioning should also be assessed as part of a comprehensive evaluation of a child with OCD (Lewin in press). Factors such as increased family accommodation of OCD symptoms have been linked to more treatment-refractory symptoms (Ferrao et al. 2006) and increased clinical severity (Peris et al. 2008; Storch et al. 2007), whereas decreases in family accommodation over the course of treatment is linked with better outcomes (Merlo et al. 2009). General family functioning measures (e.g., the Family Environment Scale [FES; Moos and Moos 1981]) are commonly used in research assessments with families of youth with OCD. Measures assessing family functioning aspects specific to OCD are also informative. For example, the Family Accommodation Scale (Calvocoressi et al. 1995) assesses the degree to which relatives of people with OCD have accommodated patient rituals over the preceding month. The FAS has been successfully adapted as parent/self report measures (e.g., Geffken et al. 2006; Peris et al. 2008; Storch et al. 2007) and is easily administered in clinical and research settings.

In the clinical setting, assessments of impairment are usually conducted in the intake interview although information may be supplemented using questionnaires (e.g., via the CBCL which screens for deficits in adaptive functioning). Early assessment of psychosocial deficits not only aids the clinician in conceptualizing the patient's treatment and clinical severity, but can be used in the process of therapy. For example, a parent may discuss significant family conflict related to OCD in the intake. However, later in therapy, the same parent may express ambivalence about E/RP exercises (e.g., reluctance to have the child participate in exposures, or feeling badly about withholding reassurance). In this and similar circumstances, the parent can be reminded that, "You've mentioned on several occasions that significant conflict is pervasive in your household. Perhaps we could try implementing these changes, like we've practiced in session, for a week or two at home to see if aspects of your child's behavior improve?" Similar approaches can be used with the child (e.g., using their extant impairments as motivation to attempt difficult changes). Taylor et al. (2002) suggest that assessing the nature of the patient's problems (e.g., how compulsions impact daily routine, ability to interact with peers) is much more valuable in the clinical assessment of OCD that are global measures of functioning and disability (e.g., the Clinical Global Impression CGI-see description below, GAF, and the CGAS).

\section{Evaluating Outcome and Tracking Progress}

Methodologies for assessing treatment outcome vary within the discipline of child psychiatry and even within the childhood OCD literature. Some studies define successful outcome to mean clinical remission. Clinical remission has been defined as a situation in which a patient "no longer meets syndromal criteria for the disorder and has no more than minimal symptoms (Frank et al. p. 853). An example would be a child meeting diagnostic criteria for OCD (e.g., using the ADIS-C/P) at pre-treatment/baseline but not at posttreatment (or, more conservatively, at follow-up). The Clinical Global ImpressionSeverity (CGI-S; Guy 1976) has also been used to indicate remission. The 7-point ordinal scale includes the following anchors of mental illness: 1 , normal, not at all ill; 2 , borderline ill; 3, mildly ill; 4, moderately ill; 5, markedly ill; 6, severely ill; or 7, extremely ill. 
Remission can be characterized as a rating of 1 or 2 on the CGI-S. The post-treatment CYBOCS has also been used to denote remission. Cut-off scores have varied in the child OCD literature; based on guidelines proposed by Frank et al. 1991, Simpson et al. (2006) proposed that remission for adult-OCD be considered a Y-BOCS ${ }^{1}$ score of $\leq 12$ for at least 1 week. In children, the Pediatric OCD Treatment Study (POTS 2004) employed a criteria of CY-BOCS Post-treatment score of $\leq 10$ (CY-BOCS scores range from 5 to 40) as the cutoff for responder status whereas Freeman et al. (2008) used CYBOCS $\leq 12$. Other studies have employed multiple criteria, e.g., OCD diagnosis-free on the ADIS and a CY-BOCS score of $\leq 10$ (Storch et al. 2007a, b, c). See Barrett et al. (2008) for a review.

Alternatively, clinical trials in child psychiatry may evaluate outcome on the basis of a clinical response (i.e., and objective evidence of a patient's symptom improvement; Simpson et al. 2006). Reduction in OCD symptom severity, e.g., assessed via the CY-BOCS (administered pre and post treatment), is also frequently employed to identify clinical response. For example, 'responders' may be defined as having 50\% or greater reduction in CY-BOCS scores (Benazon et al. 2002; Franklin et al. 1998; March et al. 1994; Valderhaug et al. 2007). This criterion varies-other studies have used a less conservative criteria (e.g., 25-30\% reduction; Himle et al. 2003; Martin and Thienemann 2005; Thienemann et al. 2001). The CY-BOCS may also be used to determine response effect size (e.g., comparing medication to CBT). The Clinical Global ImpressionImprovement (CGI-I; Guy 1976) is also commonly used to assess responder status. The CGI-I provides a clinician-rated ordinal global estimate of clinical improvement ranging from 1 (very much improved) to 7 (very much worse). Typically subjects receiving CGI-I of 1 (very much improved) or 2 (much improved) are considered responders. As with remission status, it is not uncommon for studies to employ multiple criteria to qualify a subject as a responder (e.g., 25\% decrease in the CY-BOCS and CGI-I = much improved or very much improved; Cook et al. 2001; March et al. 1998).

There are a number of limitations with the above methodology. First, using dichotomous outcomes for assessing both remission and responder status may be helpful in assessing group differences (e.g., between two different interventions), but provides little information on the amount of improvement for an individual. Additionally, using criteria such as ADIS OCD-diagnosis-free does not necessarily indicate a complete lack of symptoms and impairment; subclinical symptoms may remain. Conversely, patients can continue to meet diagnostic criteria for OCD despite marked clinical improvement.

In summary, although diagnostic markers are often used to assess remission status, this approach is complicated by the short time frame of some treatments, the lack of accounting for residual subclinical symptoms, and the burden of multiple administrations of diagnostic interviews. More comprehensive multi-informant outcome approaches utilizing both symptom measures and assessment of impairment, adaptive functioning, and family functioning (as indicated) are preferred. Additionally, there are advantages to obtaining multiple indicators of symptom change and functional status, preferably at multiple time points and with post-treatment follow-up data (e.g., 3, 6, 12, and 24-month follow-ups) to adequately assess response and remission.

Clinical applications: Objective evaluation of patient outcomes is becoming increasing relevant in clinical settings. These demands are being driven by managed care, third party payer systems, and even hospitals/clinic program-administrators who desire outcome data

\footnotetext{
1 Y-BOCS = Yale Brown Obsessive Compulsive Scale (Goodman et al. 1989), the adult-OCD counterpart to the CY-BOCS (items, scoring, and administration are identical but working and symptom checklist is geared towards adult OCD).
} 
to verify that services are benefiting the patient (and consequently warrant the expenditure). Given that the guidelines for reporting outcome are not always clear-cut for mental healthcare, adopting the research methodology for tracking improvement (discussed above) provides a platform for documenting care. For example, CY-BOCS interval-scale data (e.g., recorded biweekly) or percent CY-BOCS reductions can be recorded on a caseby-case basis.

Further, providing "data" to children with OCD and their parents throughout the course of treatment can be helpful. For example, a child may report that she still experiences "a lot" of obsessions. The therapist could counter by describing changes in her symptoms across sessions. For example, using a symptom checklist (see the 'Symptom Hierarchy Review Checklist;' Piacentini et al. 2007, pg. 73), a therapist can track clinician ratings of symptom improvement across a variety of symptoms (e.g., hoarding obsessions, cleaning rituals). Graphical and pictorial representations can help with younger children. Given the inherently aversive nature of E/RP, providing outcome and improvement data can be helpful, therapeutically, for motivating continued compliance with treatment (for both the parent and child). Further, objective ratings can assist the therapist in identifying improvement and for determining whether the quality/duration/type/frequency of E/RP is appropriate. Finally, tracking symptoms can assist in identifying problem areas (e.g., a patient's religious obsessions are still not improving) and for helping a child recognize improvement (given the motivational nature of this technique, we do not often recommend showing a child data suggesting lack of improvement except when noting isolated areas that may be more treatment-resistant).

\section{Assessment in the Context of Therapy (or Vice Versa)}

Assessment does not end when treatment begins. An experienced OCD clinician will make the two processes (evaluation and intervention) appear seamless to the patient-applying a therapeutic overtone and psychoeducation to the information-gathering phase while using every interaction with the patient to observe and assess a wide-range of factors. For example, early in the interview, the clinician should gather information (via interview and/ or CY-BOCS) from the child and family about specific obsessive-compulsive symptom topographies (e.g., worries about harming others, cleaning rituals, reassurance seeking), how these symptoms negatively impact the child/family (e.g., ridicule, difficulty with school, distress), insight into irrational nature of the OCD symptoms, and motivation to improve. Accordingly, the interview can be tailored specifically to the patient and initial psychoeducation can be provided in this context. For example, a child can be asked questions that not only assesses his/her knowledge and insight, but provide an opportunity for education on the prevalence/biological basis of OCD and the mechanisms of E/RP, for example: "Do you know what causes OCD?", "Have you ever met any other child with OCD?", "What happens if you obsessions are ignored [or you resist your compulsions]?", or "Did you know quite a lot of people that I work with have similar worries?" This process allows the clinician to diffuse blame (that the OCD symptoms are the child's [or a parent's] fault), and to normalize even the most bizarre OCD symptoms as something that he/she has encountered before and has improved with therapy (Lewin et al. 2006b).

Thus, the content and process of the OCD treatment starts within the context of the clinical intake, e.g., therapist case-conceptualization, patient and family psychoeducation, and establishment of trust/rapport (Lewin et al. 2006a, b; Piacentini et al. 2006). Although by necessity, the clinical intake must focus on information-gathering, it can be a 
make-or-break opportunity for the clinician to engage the patient and family. Consequently, it is important to provide a relevant model of how the patient's OCD is maintained and what must be done to interrupt the contingencies that maintain obsessive-compulsive behavior patterns (although patients/parents often desire to know a specific cause, this is likely not possible or necessary for behavioral intervention). Further, the therapist should sell his/her competency and empathy, while maintaining him/herself as a pillar unyielding to OCD symptoms (e.g., recognizing and redirecting attempts at reassurance seeking, escape, and other OCD rituals of which the patient and family may not be aware). Accordingly, parent perceptions/knowledge of OCD and family dynamics surrounding OCD should be assessed in order to identify factors that might maintain OCD (e.g., parental reassurance, escape from demand situations) as well as to diffuse parent selfblame. Although more substantial psychoeducation will be provided in the upcoming treatment sessions, the child and family responses during the intake can help the therapist to judge the family's insight, psychological mindedness, and entrenchment in the obsessive-compulsive cycle. In summary, the initial clinical assessment should be an interactive process that builds-in the initial aspects of CBT for OCD (e.g., psychoeducation, rapport building), leading up to the development of a hierarchy for E/RP.

\section{Research vs. Clinical Evaluation: A Summary}

Traditionally, assessment procedures differ depending on whether the child presents for a research study or a treatment intake. Research-based assessments are typically based on eligibility-determination, accurate diagnosis and characterization of clinical features, and-in cases of treatment trials-tracking outcomes such as improvement. Research assessments are measure-heavy and emphasize procedural consistency across subjects. Evaluators may or may not be the treating clinician and often vary considerably in their level of experience (e.g., undergraduate research assistants to doctoral level clinicians). Clinical intakes are, by nature, treatment focused. Although appropriateness for treatment is evaluated, the assessment is geared towards forming a case conceptualization and initial treatment plan. Rapport-building and elements of psychoeducation are often built-into the assessment. Information on clinical correlates and screening for comorbidity is often conducted, but for the purposes of tailoring treatment rather than for categorization. Measures may be utilized however unstructured/semi-structured clinical interviews predominate. Although there is variability, it is not uncommon for the licensed treating clinician to conduct elements of the assessment.

Fortunately, as practitioners strive to integrate evidence-based approaches, the clear division between approaches towards assessment found in research versus clinical practice is diminishing. Although clinical assessments are typically less standardized than their counterparts in an academic research setting (procedures utilized during a clinical intake may vary from clinician-to-clinician and from client-to-client), the use of structured interviews and validated measures is increasing. The trend towards increasingly systematic methodologies of formulating a diagnosis, tracking improvement and outcome, and monitoring changes in functioning offers several benefits to the patient and for providers, e.g., improved documentation, easier communication between treatment providers, and transfer-of-services between practitioners. Evidence-based assessment is relevant to psychopharmacology for OCD as well, e.g., structured approaches to Selective Serotonin Reuptake Inhibitor (SSRI) dosing that employ standardized questionnaires for measuring adverse side effects with respect to clinical improvement. Moreover, increasingly, 
managed care systems are requiring systematic documentation of diagnosis and treatment progress (improvement) in order to provide authorization for treatment. Borrowing proven assessment techniques from the research literature can improve a provider's justification in requesting services.

The exchange in approaches is not one-sided. Researchers in child OCD have much to learn from expert clinicians and applying therapeutic techniques and psychoeducation into research assessments is strongly encouraged. The tediousness and repetitiveness inherent in research assessments can be burdensome on the child and family-providing empathy, support and education (as long as it does not jeopardize the research protocol) can bolster compliance and potentially reduce attrition. As discussed above, the boundary between assessment and therapy for childhood OCD should be permeable-integrating therapeutic approaches into the assessment can facilitate the interviewer's conceptualization while beginning the treatment process for the child.

Acknowledgments Dr. Lewin acknowledges a fellowship from the Joseph Drown Foundation \& the Friends of the Semel Institute which provided resources to prepare this review.

Open Access This article is distributed under the terms of the Creative Commons Attribution Noncommercial License which permits any noncommercial use, distribution, and reproduction in any medium, provided the original author(s) and source are credited.

\section{References}

Achenbach, T. M. (1994). Child behavior checklist and related instruments. In M. E. Maruish (Ed.), The use of psychological testing for treatment planning and outcome assessment (pp. 517-549). Hillsdale, NJ: Lawrence Erlbaum Associates, Inc.

American Psychiatric Association. (2000). Diagnostic and statistical manual of mental disorders (DSM-IVTR). (4th Text Revision ed.). Washington, D.C.: American Psychiatric Association.

Barrett, P. M., Farrell, L., Pina, A. A., Peris, T. S., \& Piacentini, J. (2008). Evidence-based psychosocial treatments for child and adolescent obsessive-compulsive disorder. Journal of Clinical Child and Adolescent Psychology, 37, 131-155.

Bastiani, A. M., Altemus, M., Pigott, T. A., Rubenstein, C., Weltzin, T. E., \& Kaye, W. H. (1996). Comparison of obsessions and compulsions in patients with anorexia nervosa and obsessive compulsive disorder. Biological Psychiatry, 39, 966-969.

Benazon, N. R., Ager, J., \& Rosenberg, D. R. (2002). Cognitive behavior therapy in treatment-naive children and adolescents with obsessive-compulsive disorder: An open trial. Behavioral Research and Therapy, 40, 529-539.

Boeing, L., Murray, V., Pelosi, A., McCabe, R., Blackwood, D., \& Wrate, R. (2007). Adolescent-onset psychosis: Prevalence, needs and service provision. British Journal of Psychiatry, 190, 18-26.

Brown, T. A., Moras, K., Zinbarg, R. E., \& Barlow, D. H. (1993). Diagnostic and symptom distinguishability of generalized anxiety disorder and obsessive-compulsive disorder. Behavior Therapy, 24, 227-240.

Calvocoressi, L., Lewis, B., Harris, M., Trufan, S. J., Goodman, W. K., McDougle, C. J., et al. (1995). Family accommodation in obsessive-compulsive disorder. American Journal of Psychiatry, 152, 441-443.

Castellanos, F. X. (1998). Tic disorders and obsessive-compulsive disorder. In D. J. Cohen, R. D. Bruun, \& J. F. Leckman (Eds.), Child psychopharmacology (pp. 1-28). New York: Wiley.

Conners, C. K., Sitarenios, G., Parker, J. D., \& Epstein, J. N. (1998). The revised conners' parent rating scale (CPRS-R): Factor structure, reliability, and criterion validity. Journal of Abnormal Child Psychology, 26, 257-268.

Cook, E. H., Wagner, K. D., March, J. S., Biederman, J., Landau, P., Wolkow, R., et al. (2001). Long-term sertraline treatment of children and adolescents with obsessive-compulsive disorder. Journal of the American Academy of Child and Adolescent Psychiatry, 40, 1175-1181. 
Ferrao, Y. A., Shavitt, R. G., Bedin, N. R., de Mathis, M. E., Carlos, L. A., Fontenelle, L. F., et al. (2006). Clinical features associated to refractory obsessive-compulsive disorder. Journal of Affective Disorders, 94, 199-209.

Foa, E. B., Kozak, M. J., Goodman, W. K., Hollander, E., Jenike, M. A., \& Rasmussen, S. A. (1995). DSMIV field trial: Obsessive-compulsive disorder. American Journal of Psychiatry, 152, 90-96.

Frank, E., Prien, R. F., Jarrett, R. B., Keller, M. B., Kupfer, D. J., Lavori, P. W., et al. (1991). Conceptualization and rationale for consensus definitions of terms in major depressive disorder. Remission, recovery, relapse, and recurrence. Archives of General Psychiatry, 48, 851-855.

Franklin, M. E., Kozak, M. J., Cashman, L. A., Coles, M. E., Rheingold, A. A., \& Foa, E. B. (1998). Cognitive-behavioral treatment of pediatric obsessive-compulsive disorder: An open clinical trial. Journal of the American Academy of Child and Adolescent Psychiatry, 37, 412-419.

Freeman, J. B., Garcia, A. M., Coyne, L., Ale, C., Przeworski, A., Himle, M., et al. (2008). Early childhood OCD: Preliminary findings from a family-based cognitive-behavioral approach. Journal of the American Academy of Child and Adolescent Psychiatry, 47, 593-602.

Gallant, J., Storch, E. A., Merlo, L. J., Ricketts, E. D., Geffken, G. R., Goodman, W. K., et al. (2008). Convergent and discriminant validity of the children's Yale-brown obsessive compulsive scalesymptom checklist. Journal of Anxiety Disorders, 22, 1369-1376.

Geffken, G. R., Storch, E. A., Duke, D. C., Monaco, L., Lewin, A. B., \& Goodman, W. K. (2006). Hope and coping in family members of patients with obsessive-compulsive disorder. Journal of Anxiety Disorders, 20, 614-629.

George, M. S., Trimble, M. R., Ring, H. A., Sallee, F. R., \& Robertson, M. M. (1993). Obsessions in obsessive-compulsive disorder with and without Gilles de la Tourette's syndrome. American Journal of Psychiatry, 150, 93-97.

Godart, N. T., Flament, M. F., Perdereau, F., \& Jeammet, P. (2002). Comorbidity between eating disorders and anxiety disorders: A review. International Journal of Eating Disorders, 32, 253-270.

Goodman, W. K., Price, L. H., Rasmussen, S. A., Mazure, C., Fleischmann, R. L., Hill, C. L., et al. (1989). The Yale-brown obsessive-compulsive scale: Development, use and reliability. Archives of General Psychiatry, 46, 1006-1011.

Goodman, W. K., Storch, E. A., Geffken, G. R., \& Murphy, T. K. (2006). Obsessive-compulsive disorder in Tourette syndrome. Journal of Child Neurology, 21, 704-714.

Grabill, K., Merlo, L., Duke, D., Harford, K. L., Keeley, M. L., Geffken, G. R., et al. (2008). Assessment of obsessive-compulsive disorder: A review. Journal of Anxiety Disorders, 22, 1-17.

Guy, W. (1976). Clinical global impressions. In Revised DHEW Pub. (ADM (Ed.), ECDEU assessment manual for psychopharmacology (pp. 218-222). Rockville, MD: National Institute for Mental Health.

Hanna, G. L., Piacentini, J., Cantwell, D. P., Fischer, D. J., Himle, J. A., \& Van Etten, M. (2002). Obsessivecompulsive disorder with and without tics in a clinical sample of children and adolescents. Depression and Anxiety, 16, 59-63.

Himle, J. A., Fischer, D. J., Van Etten, M. L., Janeck, A. S., \& Hanna, G. L. (2003). Group behavioral therapy for adolescents with tic-related and non-tic-related obsessive-compulsive disorder. Depression and Anxiety, 17, 73-77.

Holzer, J. C., Goodman, W. K., McDougle, C. J., Baer, L., Boyarsky, B. K., Leckman, J. F., et al. (1994). Obsessive-compulsive disorder with and without a chronic tic disorder. A comparison of symptoms in 70 patients. British Journal of Psychiatry, 164, 469-473.

Huppert, J. D., Simpson, H. B., Nissenson, K. J., Liebowitz, M. R., \& Foa, E. B. (2009). Quality of life and functional impairment in obsessive-compulsive disorder: A comparison of patients with and without comorbidity, patients in remission, and healthy controls. Depression and Anxiety, 26, 39-45.

Insel, T. R., \& Akiskal, H. S. (1986). Obsessive-compulsive disorder with psychotic features: A phenomenologic analysis. American Journal of Psychiatry, 143, 1527-1533.

Ivarsson, T., Melin, K., \& Wallin, L. (2008). Categorical and dimensional aspects of co-morbidity in obsessive-compulsive disorder (OCD). European Child and Adolescent Psychiatry, 17, 20-31.

Jenike, M. A. (1989). Obsessive-compulsive and related disorders: A hidden epidemic. New England Journal of Medicine, 321(8), 539-541.

Jimenez-Murcia, S., Fernandez-Aranda, F., Raich, R. M., Alonso, P., Krug, I., Jaurrieta, N., et al. (1997). Obsessive-compulsive and eating disorders: Comparison of clinical and personality features. Psychiatry and Clinical Neurosciences, 61(4), 385-391.

Kaufman, J., Birmaher, B., Brent, D., Rao, U., Flynn, C., Moreci, P., et al. (1997). Schedule for affective disorders and schizophrenia for school-age children-present and lifetime version (K-SADS-PL): Initial reliability and validity data. Journal of the American Academy of Child and Adolescent Psychiatry, 36, 980-988. 
King, R. A., \& Scahill, L. (1999). The assessment and coordination of treatment of children and adolescents with OCD. Child and Adolescent Psychiatric Clinics of North America, 8, 577-597. xi.

Kovacs, M. (1992). Manual for children's depression inventory. Toronto: Multi-Health Systems, Inc.

Langley, A. K., Bergman, R. L., \& Piacentini, J. C. (2002). Assessment of childhood anxiety. International Review of Psychiatry, 14, 101-113.

Leckman, J. F., Grice, D. E., Barr, L. C., de Vries, A. L., Martin, C., Cohen, D. J., et al. (1994). Tic-related vs. non-tic-related obsessive compulsive disorder. Anxiety, 1, 208-215.

Leckman, J. F., Riddle, M. A., Hardin, M. T., Ort, S. I., Swartz, K. L., Stevenson, J., et al. (1989). The Yale global tic severity scale: Initial testing of a clinician-rated scale of tic severity. Journal of the American Academy of Child and Adolescent Psychiatry, 28, 566-573.

Lewin, A. B. (in press). Parent training for childhood anxiety. In D. McKay \& E. Storch (Eds.), Handbook of child and adolescent anxiety disorders.

Lewin, A. B., Bergman, R. L., Peris, T. S., Chang, S., McCracken, J. T., \& Piacentini, J. (in press-a). Correlates of insight among youth with obsessive compulsive disorder. Journal of Child Psychology and Psychiatry. doi:10.1111/j.1469-7610.2009.02181.x.

Lewin, A. B., Chang, S., McCracken, J., McQueen, M., \& Piacentini, J. (in press-b). Comparison of clinical features among youth with tic disorders, obsessive-compulsive disorder (OCD), and both conditions. Psychiatry Research.

Lewin, A. B., \& Piacentini, J. (2009). Obsessive-compulsive disorder in children. In B. J. Sadock, V. A. Sadock, \& P. Ruiz (Eds.), Kaplan \& Sadock's comprehensive textbook of psychiatry (9th ed., pp. 3671-3678). Philadelphia: Lippincott, Williams \& Wilkins.

Lewin, A. B., Storch, E. A., Adkins, J., Murphy, T. K., \& Geffken, G. R. (2005). Current directions in pediatric obsessive-compulsive disorder. Pediatric Annals, 34, 128-134.

Lewin, A. B., Storch, E. A., Geffken, G. R., Goodman, W. K., \& Murphy, T. K. (2006a). A neuropsychiatric review of pediatric obsessive-compulsive disorder: Etiology and efficacious treatments. Neuropsychiatric Disease and Treatment, 2, 21-31.

Lewin, A. B., Storch, E. A., Merlo, L. J., Adkins, J. W., Murphy, T. K., \& Geffken, G. R. (2006b). Intensive cognitive behavioral therapy for pediatric obsessive compulsive disorder: A treatment protocol for mental health providers. Psychological Services, 2, 91-104.

Mansueto, C. S., \& Keuler, D. J. (2005). Tic or compulsion?: It's Tourettic OCD. Behavioral Modification, 29, 784-799.

March, J. S., Biederman, J., Wolkow, R., Safferman, A., Mardekian, J., Cook, E. H., et al. (1998). Sertraline in children and adolescents with obsessive-compulsive disorder: A multicenter randomized controlled trial. JAMA, 280(20), 1752-1756.

March, J. S., Franklin, M. E., Leonard, H., Garcia, A., Moore, P., Freeman, J., et al. (2007). Tics moderate treatment outcome with sertraline but not cognitive-behavior therapy in pediatric obsessive-compulsive disorder. Biological Psychiatry, 61, 344-347.

March, J. S., Mulle, K., \& Herbel, B. (1994). Behavioral psychotherapy for children and adolescents with obsessive-compulsive disorder: An open trial of a new protocol-driven treatment package. Journal of the American Academy of Child and Adolescent Psychiatry, 33, 333-341.

March, J. S., Parker, J. D., Sullivan, K., Stallings, P., \& Conners, C. K. (1997). The multidimensional anxiety scale for children (MASC): Factor structure, reliability, and validity. Journal of the American Academy of Child and Adolescent Psychiatry, 36, 554-565.

Martin, J. L., \& Thienemann, M. (2005). Group cognitive-behavior therapy with family involvement for middle-school-age children with obsessive-compulsive disorder: A pilot study. Child Psychiatry and Human Development, 36, 113-127.

Merlo, L. J., Lehmkuhl, H. D., Geffken, G. R., \& Storch, E. A. (2009). Decreased family accommodation associated with improved therapy outcome in pediatric obsessive-compulsive disorder. Journal of Consulting and Clinical Psychology, 77, 355-360.

Merlo, L. J., Storch, E. A., Murphy, T. K., Goodman, W. K., \& Geffken, G. R. (2005). Assessment of pediatric obsessive-compulsive disorder: A critical review of current methodology. Child Psychiatry and Human Development, 36, 195-214.

Moos, R., \& Moos, B. (1981). Family environmental scale manual. Palo Alto, CA: Consulting Psychologists Press.

Pauls, D. L., Alsobrook, J. P., Goodman, W., Rasmussen, S., \& Leckman, J. F. (1995). A family study of obsessive-compulsive disorder. American Journal of Psychiatry, 152, 76-84.

Pediatric OCD Treatment Study. (2004). Cognitive-behavior therapy, sertraline, and their combination for children and adolescents with obsessive-compulsive disorder: The pediatric OCD treatment study (POTS) randomized controlled trial. JAMA, 292, 1969-1976. 
Peris, T. S., Bergman, R. L., Langley, A., Chang, S., McCracken, J. T., \& Piacentini, J. (2008). Correlates of accommodation of pediatric obsessive-compulsive disorder: Parent, child, and family characteristics. Journal of the American Academy of Child and Adolescent Psychiatry.

Piacentini, J., Bergman, R. L., Keller, M., \& McCracken, J. (2003). Functional impairment in children and adolescents with obsessive-compulsive disorder. Journal of Child and Adolescent Psychopharmacology, 13(Suppl 1), S61-S69.

Piacentini, J., \& Chang, S. W. (2006). Behavioral treatments for tic suppression: Habit reversal training. Advances in Neurology, 99, 227-233.

Piacentini, J. C., March, J. S., \& Franklin, M. E. (2006). Cognitive-behavioral therapy for youth with obsessive-compulsive disorder. In P. C. Kendall (Ed.), Child and adolescent therapy: Cognitivebehavioral procedures (3rd ed., pp. 297-321). New York, NY: Guilford Press.

Piacentini, J., Peris, T. S., Bergman, R. L., Chang, S., \& Jaffer, M. (2007). Functional impairment in childhood OCD: Development and psychometrics properties of the child obsessive-compulsive impact scale-revised (COIS-R). Journal of Clinical Child and Adolescent Psychology, 36, 645-653.

Reynolds, C. R., \& Kamphaus, R. W. (2002). A clinician's guide to the behavioral assessment system for children (BASC). Needham Heights, MA: Allyn \& Bacon.

Rodowski, M. F., Cagande, C. C., \& Riddle, M. A. (2008). Childhood obsessive-compulsive disorder presenting as schizophrenia spectrum disorders. Journal of Child and Adolescent Psychopharmacology, 18, 395-401.

Scahill, L., Riddle, M. A., McSwiggin-Hardin, M., Ort, S. I., King, R. A., Goodman, W. K., et al. (1997). Children's Yale-Brown Obsessive Compulsive Scale: Reliability and validity. Journal of the American Academy of Child and Adolescent Psychiatry, 36(6), 844-852.

Shaffer, D., Fisher, P., Lucas, C. P., Dulcan, M. K., \& Schwab-Stone, M. E. (2000). NIMH diagnostic interview schedule for children version IV (NIMH DISC-IV): Description, differences from previous versions, and reliability of some common diagnoses. Journal of the American Academy of Child and Adolescent Psychiatry, 39, 28-38.

Shaffer, D., Gould, M. S., Brasic, J., Ambrosini, P., Fisher, P., Bird, H., et al. (1983). A children's global assessment scale (CGAS). Archives of General Psychiatry, 40, 1228-1231.

Silverman, W. K., \& Albano, A. M. (1996). The anxiety disorders interview schedule for DSM-IV-Child and parent versions. San Antonio, TX: Graywinds Publications.

Silverman, W. K., Saavedra, L. M., \& Pina, A. A. (2001). Test-retest reliability of anxiety symptoms and diagnoses with the anxiety disorders interview schedule for DSM-IV: Child and parent versions. Journal of the American Academy of Child and Adolescent Psychiatry, 40, 937-944.

Simpson, H. B., Huppert, J. D., Petkova, E., Foa, E. B., \& Liebowitz, M. R. (2006). Response versus remission in obsessive-compulsive disorder. Journal of Clinical Psychiatry, 67, 269-276.

Storch, E. A., Geffken, G. R., Merlo, L. J., Jacob, M. L., Murphy, T. K., Goodman, W. K., et al. (2007a). Family accommodation in pediatric obsessive-compulsive disorder. Journal of Clinical Child and Adolescent Psychology, 36, 207-216.

Storch, E. A., Geffken, G. R., Merlo, L. J., Mann, G., Duke, D., Munson, M., et al. (2007b). Family-based cognitive-behavioral therapy for pediatric obsessive-compulsive disorder: Comparison of intensive and weekly approaches. Journal of the American Academy of Child and Adolescent Psychiatry, 46, 469-478.

Storch, E. A., Murphy, T. K., Adkins, J. W., Lewin, A. B., Geffken, G. R., Johns, N. B., et al. (2006). The children's Yale-brown obsessive-compulsive scale: Psychometric properties of child- and parent-report formats. Journal of Anxiety Disorders, 20, 1055-1070.

Storch, E. A., Stigge-Kaufman, D., Marien, W. E., Sajid, M., Jacob, M. L., Geffken, G. R., et al. (2007c). Obsessive-compulsive disorder in youth with and without a chronic tic disorder. Depression and Anxiety, 25, 761-767.

Storch, E. A., Stigge-Kaufman, D., Marien, W. E., Sajid, M., Jacob, M. L., Geffken, G. R., et al. (2008). Obsessive-compulsive disorder in youth with and without a chronic tic disorder. Depression and Anxiety, 25, 761-767.

Strober, M., Freeman, R., Lampert, C., \& Diamond, J. (2007). The association of anxiety disorders and obsessive compulsive personality disorder with anorexia nervosa: Evidence from a family study with discussion of nosological and neurodevelopmental implications. International Journal of Eating Disorders, 40(Suppl), S46-S51.

Swanson, J. M. (1992). School-based assessments and interventions for ADD students. Irvine, CA: K.C. Publications.

Swedo, S. E., Rapoport, J. L., Leonard, H., Lenane, M., \& Cheslow, D. (1989). Obsessive-compulsive disorder in children and adolescents. Clinical phenomenology of 70 consecutive cases. Archives of General Psychiatry, 46, 335-341. 
Taylor, S., Thordarson, D. S., \& Sochting, I. (2002). Obsessive-compulsive disorder. In M. M. Antony \& D. H. Barlow (Eds.), Handbook of assessment and treatment planning for psychological disorders (pp. 182-214). New York: Guildord Press.

Thienemann, M., Martin, J., Cregger, B., Thompson, H. B., \& Dyer-Friedman, J. (2001). Manual-driven group cognitive-behavioral therapy for adolescents with obsessive-compulsive disorder: A pilot study. Journal of the American Academy of Child and Adolescent Psychiatry, 40, 1254-1260.

Turner, S. M., Beidel, D. C., \& Stanley, M. A. (1992). Are obessional thoughts and worry different cognititve phenomena? Clinical Psychology Review, 12, 257-270.

Valderhaug, R., Larsson, B., Gotestam, K. G., \& Piacentini, J. (2007). An open clinical trial of cognitivebehaviour therapy in children and adolescents with obsessive-compulsive disorder administered in regular outpatient clinics. Behavioral Research and Therapy, 45, 577-589.

Wood, J. J., Piacentini, J. C., Bergman, R. L., McCracken, J., \& Barrios, V. (2002). Concurrent validity of the anxiety disorders section of the anxiety disorders interview schedule for DSM-IV: Child and parent versions. Journal of Clinical Child and Adolescent Psychology, 31, 335-342.

Zohar, A. H. (1999). The epidemiology of obsessive-compulsive disorder in children and adolescents. Child and Adolescent Psychiatric Clinics of North America, 8, 445-460. 